resistant Staphylococcus aureus from a health care center ward and associated nursing home. Arch Intern Med 2001; 161:859-863.

11. Jones PG, Sura T, Harris M, Strother A. Mupirocin resistance in clinical isolates of Staphylococcus aureus. Infect Control Hosp Epidemiol 2003; 24: 300-301.

12. Soto NE, Vaghjimal A, Stahl-Avicolli A, Protic JR, Lutwick LI, Chapnick E. Bacitracin versus muipirocin for Staphylococcus aureus nasal colonization. Infect Control Hosp Epidemiol 1999; 20:351-353.

\section{The Growth of Infection Control, Impact of ICHE, and Challenges Ahead}

TO THE EDITOR-In preparing for the president's address at the 2005 Society for Health Care Epidemiology (SHEA) Annual Meeting, I sought to measure the growth of infection control as a field of endeavor, determine the impact of $I n$ fection Control and Hospital Epidemiology (ICHE), and record our past leaders' opinions about the success of SHEA and its future challenges. Using Science Citation Index Expanded (SCIE), I performed a literature search in March 2005 for published articles written in any language, using "infection control" as the subject search term. A comparison of hits during 5-year increments from 1990 through 2004 revealed a nearly a 3 -fold incremental increase in the number of infection control-related articles that were published (Figure 1). It takes a few years before key articles become widely known and cited in the literature. SCIE was searched using "Infect Control Hosp Epidemiol" as the cited-work search term starting in 1985 to determine how often articles published in ICHE appeared in bibliographies of articles in print. A comparison of hits during 5-year increments revealed that, between 1985 and 1999, there was greater than a 2-fold incremental increase in the citation of articles published in

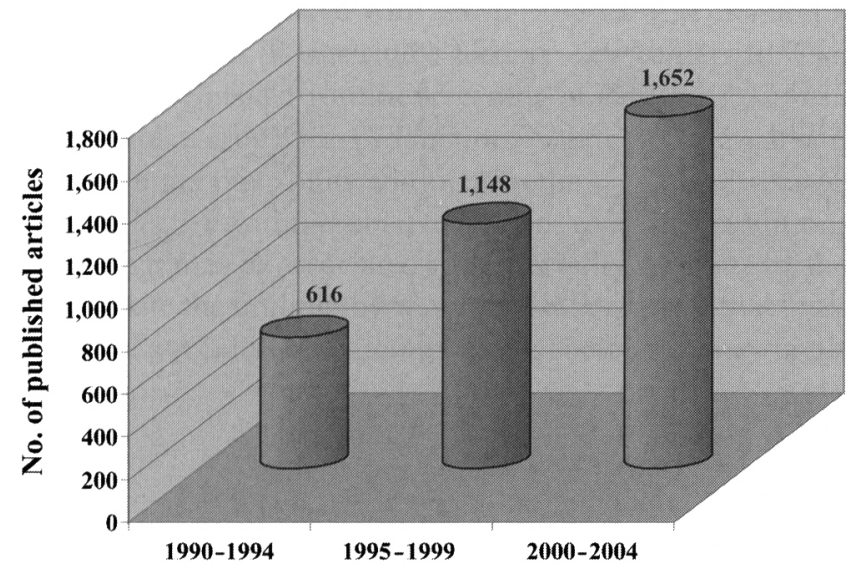

FIGURE 1. The number of published articles revealed during a search of Science Citation Index Expanded with "infection control" as the search term.
ICHE (Figure 2). Together, these data suggest that infection control as a field of scientific endeavor is growing steadily and that, in addition to the known impact factor of $I C H E$, publications in our society's journal are read and quoted with increasing frequency.

I queried the 24 past SHEA presidents and used a modified Delphi process to analyze their insight into the accomplishments of and future challenge for our society. When the past SHEA presidents were asked to report SHEA's most important contribution during the last 25 years, the consensus opinion was (1) the identification of infection control and healthcare epidemiology as a discipline, (2) the inauguration of the SHEA Annual Meeting, and (3) the creation of ICHE. When they were asked to report the greatest future challenge for SHEA, the consensus was to further enhance a rigorous evidence-based approach to this discipline.

Infection control and healthcare epidemiology is undeniably an established and growing field of endeavor that is in step with the steadily increasing impact of our society's journal. To continue the momentum, we must share our enthusiasm with medical, nursing, and public health students, as well as nurses and house staff; nurture SHEA fellows; and remain true to ourselves.

Leonard A. Mermel, DO, ScM

Dr. Mermel is from the Division of Infectious Diseases, Rhode Island Hospital and the Department of Medicine, Brown Medical School, Providence, Rhode Island.

Address reprint requests to Leonard A. Mermel, DO, ScM, Division of Infectious Diseases, Rhode Island Hospital, 593 Eddy Street, Providence, RI 02903 (lmermel@lifespan.org).

Infect Control Hosp Epidemiol 2006; 27:325

(C) 2006 by The Society for Healthcare Epidemiology of America. All rights reserved. 0899-823X/2006/2703-0022\$15.00.

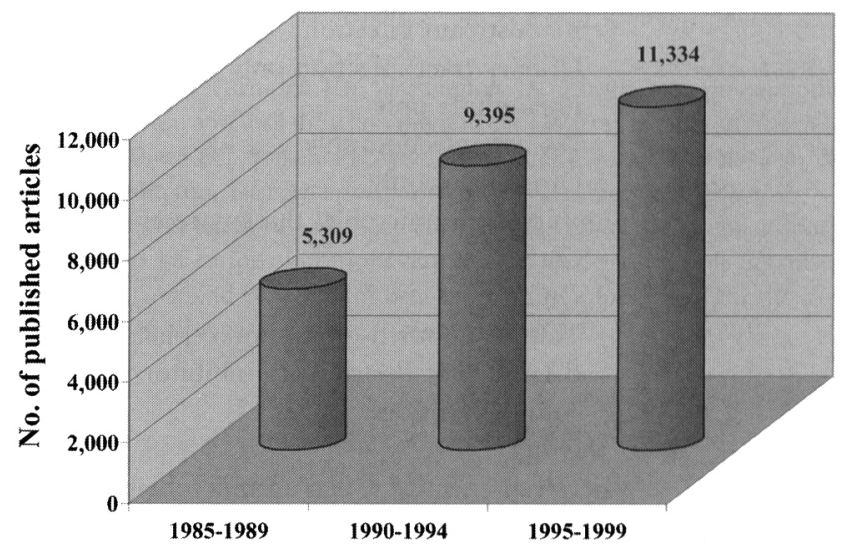

FIGURE 2. The number of published articles revealed during a search of Science Citation Index Expanded with "Infect Control Hosp Epidemiol" as the search term. 